\title{
Synthesis and Characterization of Modified Kaolin-Bentonite Composites for Enhanced Fluoride Removal from Drinking Water
}

\author{
Ebenezer Annan, ${ }^{1}$ Emmanuel Nyankson, ${ }^{1}$ Benjamin Agyei-Tuffour ${ }^{\mathbb{D}}{ }^{1}$ \\ Stephen Kofi Armah, ${ }^{1}$ George Nkrumah-Buandoh, ${ }^{2}$ Joanna Aba Modupeh Hodasi, ${ }^{2}$ \\ and Michael Oteng-Peprah ${ }^{3}$ \\ ${ }^{1}$ Department of Materials Science and Engineering, School of Engineering Sciences, College of Basic and Applied Sciences, \\ University of Ghana, Accra, Ghana \\ ${ }^{2}$ Department of Physics, School of Physical and Mathematical Sciences, College of Basic and Applied Sciences, \\ University of Ghana, Accra, Ghana \\ ${ }^{3}$ Department of Water and Sanitation, University of Cape Coast, Cape Coast, Ghana
}

Correspondence should be addressed to Benjamin Agyei-Tuffour; bagyei-tuffour@ug.edu.gh

Received 10 October 2020; Revised 9 December 2020; Accepted 5 January 2021; Published 16 January 2021

Academic Editor: Lingxue Kong

Copyright (c) 2021 Ebenezer Annan et al. This is an open access article distributed under the Creative Commons Attribution License, which permits unrestricted use, distribution, and reproduction in any medium, provided the original work is properly cited.

\begin{abstract}
Fluoride-contaminated drinking waters are known to cause severe health hazards such as fluorosis and arthritis. This paper presents the encapsulation of iron oxide nanoparticles in kaolin-bentonite composites adsorbents (KBNPs) for the removal of fluoride from drinking water by adsorption compared with kaolin-bentonite composite (KB). Adsorbents with an average weight of $\sim 200 \mathrm{mg}$ and $\sim 7 \mathrm{~mm}$ diameter (granules) were prepared in the ratio of 10:10:0.1 for kaolinite, bentonite, and magnetite nanoparticles, respectively. The granules were air-dried and calcined at $750^{\circ} \mathrm{C}$ and contacted with $2 \mathrm{mg} / \mathrm{L}$ sodium fluoride solution at varying time periods. The adsorbents were characterized using Fourier transform infrared spectroscopy (FTIR), scanning electron microscopy (SEM) formulation, and Brunauer-Emmett-Teller (BET), whereas the adsorption mechanism and the kinetics were explained using the Langmuir isotherm, Freundlich models, and pseudo-first-order and pseudo-second-order models. The results showed that the BET surface areas for the granules were $10 \mathrm{~m}^{2} / \mathrm{g}$ and $3 \mathrm{~m}^{2} / \mathrm{g}$ for KBNPs and KB, respectively. The SEM images for the adsorbents before and after adsorption confirm the plate-like morphology of kaolin and bentonite. The FTIR analyses of bentonite $\left(3550 \mathrm{~cm}^{-1}-4000 \mathrm{~cm}^{-1}\right)$ and kaolin $\left(400-1200 \mathrm{~cm}^{-1}\right)$ correspond to the structural hydroxyl groups and water molecules in the interlayer space of bentonites and the vibrational modes of $\mathrm{SiO}_{4}$ tetrahedron of kaolin, respectively. The KBNPs composites also recorded a fluoride removal efficiency of $\sim 91 \%$ after 120 minutes compared with $64 \%$ for KB composites without $\mathrm{Fe}_{3} \mathrm{O}_{4}$ nanoparticles. The adsorptions of fluoride by the KBNPs and $\mathrm{KB}$ granules were found to agree with the Freundlich isotherm and a pseudo-second-order kinetic model, respectively. The results clearly show that the impregnation of clays with magnetite nanoparticles has significant effect in the removal of fluoride, and the implication of the results has been discussed to show the impact of clay-magnetite nanoparticles composites in the removal of fluoride from contaminated water.
\end{abstract}

\section{Introduction}

Fluoride contamination in drinking water is commonly associated with groundwater sources due to demineralization. The effects of the contamination depend on the fluoride concentration and the duration of continuous uptake. Fluoride content in drinking water can be beneficial or detrimental to human health. The World Health
Organization (WHO) recommends a fluoride intake of less than $1.5 \mathrm{mg} / \mathrm{L}$ [1]. Small amounts, less than $1.0 \mathrm{mg} / \mathrm{L}$, of fluoride in ingested water are usually considered to have beneficial effects on the teeth and skeletal systems and have been shown to decrease the rate of occurrence of dental cavities, particularly among children [2]. However, excess intake of fluoride $(>1.5 \mathrm{mg} / \mathrm{L})$ leads to various diseases such as fluorosis, arthritis, and brittle bones [3, 4]. Dental 
fluorosis is a common symptom of high fluoride ingestion which is classified by water with fluoride concentration between 1.5 and $4 \mathrm{mg} / \mathrm{L}$. The mottling of teeth in mild cases and embrittlement of bones are signs of dental and skeletal fluorosis for water ingested with fluoride concentrations between 4 and $10 \mathrm{mg} / \mathrm{L}$ [5].

Fluoride is widely distributed in geological environment [5] and generally released into the groundwater by slow dissolution of fluorine-containing rocks [6]. Various minerals, for example, fluorite, biotite, and topaz and their corresponding host rocks such as granite, basalt, syenite, and shale, contain fluoride that can be released into the groundwater $[7,8]$. Thus, groundwater is a major source of human intake of fluoride. Besides the natural geological sources for fluoride enrichment in groundwater, various fluorochemical industries such as aluminum smelting are also contributors to fluoride pollution [9].

Fluoride concentration levels in groundwater in many African countries have been reported by Kut et al. [10] and Ghana is reported to have concentrations greater than $4 \mathrm{mg}$ / $\mathrm{L}$ in the Bongo and Bolgatanga districts in the northern regions $[11,12]$. Indeed, some municipalities within the above-mentioned districts have recorded fluoride concentrations in groundwater to be as high as $12 \mathrm{mg} / \mathrm{L}$ [12]. It is therefore critical to consider the treatment of fluoridecontaminated water in these locations. The use of clay materials and coagulation and precipitation, membrane filtration, electrochemical processes, and adsorption techniques are among the methods used in the removal of fluoride from potable groundwater sources. Adsorption processes are economical especially in cases where adsorbents are made from indigenous materials and a previous study by Puka [13] reports fluoride adsorption on clays which contains oxides of iron, aluminum, and silicon.

Other adsorbents that have been reported for the removal of fluoride from water include activated and impregnated alumina [14-16], rare Earth oxides [17], activated clay $[13,18]$, impregnated silica [19], carbonaceous materials [20], solid industrial wastes like red mud, spent catalysts, and fly ash [21, 22], zeolites and related ion exchangers [23], and biosorbents [24]. Iron oxide, usually in red mud, clays, and other deposits, has been reported as better adsorbent in comparison with other adsorbents for removal of fluoride [25]. This is due to the fact that the high affinity for ion exchange is such situations when fluoride is attached to other support structures. Tomar and Kumar have also indicated that a mixture of metallic oxides enhances fluoride adsorption [26]. Composites chromium (III)-zirconia bimetallic oxide and zirconium iron oxide/clay are also documented to show good removal rate for fluorides [27]. The removal of fluoride with kaolinite $(\sim 18.2 \%)$ and bentonite $(\sim 46 \%)$, respectively, has been reported by Mohapatra et al. [28] and Kau et al. [29] who reported bentonite to possess higher fluoride adsorption capacity than kaolinite. The maximum adsorption efficiencies for iron oxide coatedkaolinite and iron oxide coated-bentonite clays are known to be $61 \%$ and $80 \%$, respectively, according to Puka [13]. However, the authors are unware of any published study that has formed kaolin and bentonite composites impregnated with iron oxide nanoparticles for the removal of fluorides from contaminated groundwater.

Hence, in this research, kaolinite $(\mathrm{K})$ and bentonite (B) composites impregnated with iron oxide nanoparticles were investigated for their potential to remove fluoride ions from groundwater. Magnetite nanoparticles were mixed with the clay minerals into granules and subjected to adsorption studies. Scanning electron microscopy (SEM), Fourier transform infrared spectroscopy (FTIR), and Brunauer-Emmett-Teller (BET) analyses performed on the composites and the adsorption kinetics were explained using the Langmuir, Freundlich, and pseudo-first-order and pseudo-second-order models.

\section{Materials and Methods}

All chemicals used were of analytical grade and were obtained from Sigma-Aldrich, United Kingdom. Magnetite nanoparticles, $\mathrm{Fe}_{3} \mathrm{O}_{4}$ with particle size range of $50-100 \mathrm{~nm}$, bentonite clay (item number 682659), and kaolinite (item number 03584), were acquired from Sigma-Aldrich.

2.1. Preparation of Adsorbents. The adsorbents were prepared in the ratio of 10:10:0.1 by weight for kaolinite, bentonite, and magnetite nanoparticles, respectively. The compositions were thoroughly mixed and granules with diameter of $0.5-0.7 \mathrm{~cm}$ range and an average weight of $250 \mathrm{mg}$ were formulated. The green granules were air-dried and subsequently calcined at $750^{\circ} \mathrm{C}$. During the calcination, an initial ramp of $5^{\circ} \mathrm{C} / \mathrm{min}$ was used for 30 minutes before it was increased to $10^{\circ} \mathrm{C} / \mathrm{min}$ for the remaining period until the maximum temperature. The temperature was then maintained at $750^{\circ} \mathrm{C}$ for 30 minutes before self-cooling to ambient temperature. The granules shown in Figure 1 are the green bodies (Figures 1(a) and 1(c)) and the calcined granules (Figures 1(b) and 1(d)). The calcined granules' brown-red coloration is due to the presence of iron.

2.2. Characterization of Adsorbents. The calcined granule weighing $\sim 200 \mathrm{mg}$ was subjected to surface area and pore size analysis with nitrogen gas physisorption at $77 \mathrm{~K}$ using a Micromeritics ASAP 2020 (Micrometrics Instrument Corporation, Norcross, USA). The surface area was calculated using BET (Brunauer-Emmett-Teller) method for relative pressures between $\left(P / P_{0}\right)=0.05-0.3$. The pore size was estimated with the BJH (Barrett-Joyner-Halenda) method using the desorption data. The samples were degassed at $393 \mathrm{~K}$ for 2 hours before the nitrogen gas adsorption intrusion analysis. The FTIR analysis was performed with PerkinElmer Frontier (Perkin Elmer, Ohio, USA) and TESCAN MIRA3 FEG-Scanning Electron Microscope (TESCAN, United Kingdom) was used to obtain microimages.

2.3. Batch Adsorption Experiments. Fluoride solutions were prepared by diluting the prepared stock solution $(100 \mathrm{mg} / \mathrm{L}$ fluoride) to $2 \mathrm{mg} / \mathrm{L}$. The adsorption experiments were 


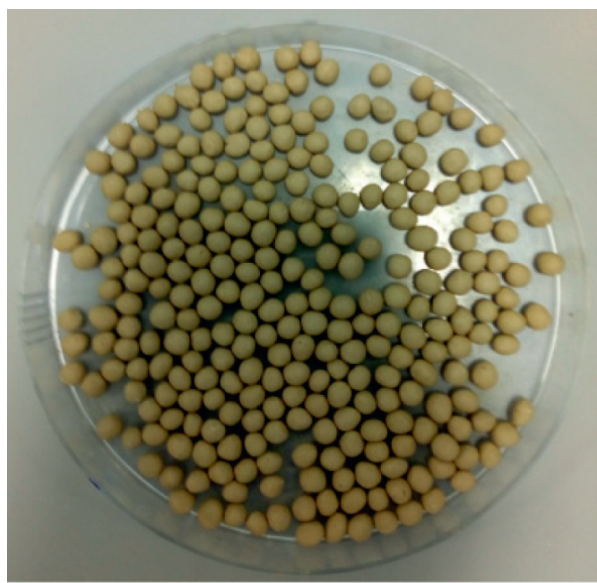

(a)

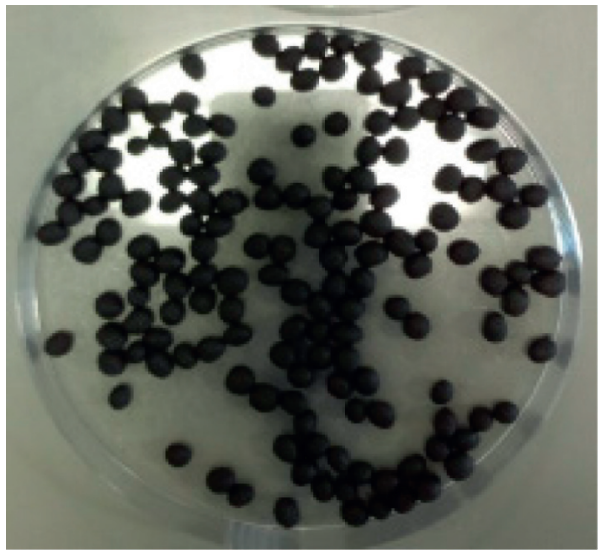

(c)

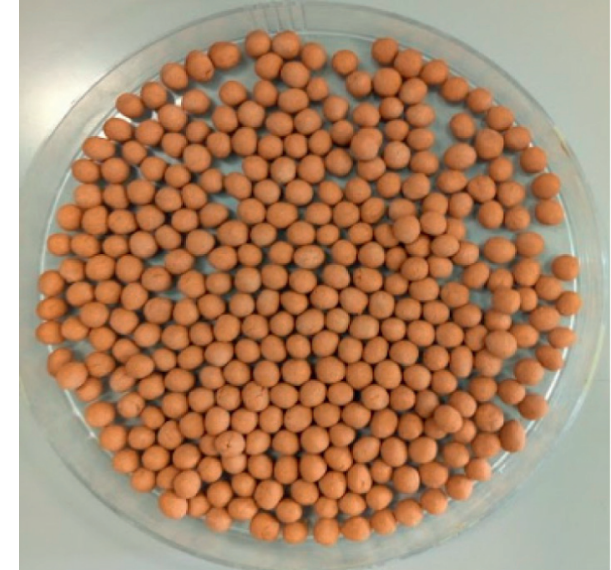

(b)

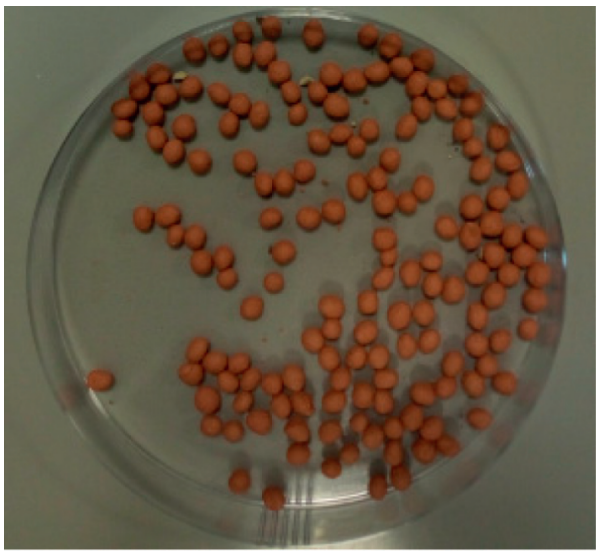

(d)

FIgURE 1: Adsorbents used in the adsorption experiments. (a) Green KB adsorbent. (b) Calcined KB adsorbent. (c) Green KBNPs adsorbent. (d) Calcined KBNPs adsorbent.

carried out in $100 \mathrm{~mL}$ beakers with $2 \mathrm{~g}$ (equivalent to 10 granules) of adsorbent granules and a liquid volume of $50 \mathrm{~mL}$ with an initial fluoride concentration of $2 \mathrm{mg} / \mathrm{L}$. The beakers were placed on an orbital shaker (STUART, Staffordshire, UK) at constant speed of $200 \mathrm{rpm}$ at $25 \pm 1^{\circ} \mathrm{C}$. After an adsorption time of 20 minutes, the granules were filtrated with $0.45 \mu \mathrm{m}$ cellulose acetate membranes and $5 \mathrm{ml}$ of TISAB 1 (Sigma-Aldrich, UK) was added to the filtered solution to maintain the ionic strength. The fluoride concentration was measured using a fluoride electrode H14110 (HANNA Instruments, Inc., Woonsocket, USA). The adsorption experiments were repeated for different adsorption times and the average removal efficiencies recorded. The percentage removal of adsorbents and kinetic modeling parameters were determined to explain the adsorbents' fluoride removal potential and mechanism. For each set of granules, the experiment was repeated thrice, and the average recorded.

Furthermore, the dosage of adsorbent for both granules was increased from 2 grams to 10 grams and the removal efficiency evaluated. The initial $\mathrm{pH}$ for experiments undertaken was within 5.5-7.5 $\mathrm{pH}$ range and equilibrium reached at a $\mathrm{pH}$ of 6.5.0. The experiment was undertaken at constant temperature of $25 \pm 1^{\circ} \mathrm{C}$. All other parameters of the experiment with regard to batch adsorption are the same, except for contact times which were 120 minutes and 140 minutes for $\mathrm{KB}$ and KBNPs, respectively. These times are when maximum removal efficiency was obtained for the respective granules. The basic Freundlich and Langmuir isotherms modeling was then undertaken and key parameters were computed.

The amount of fluoride adsorbed was calculated using the following equation:

$$
q=\left(C_{0}-C_{t}\right) \frac{V}{m},
$$

where $q$ is the fluoride adsorbed $(\mathrm{mg} / \mathrm{g}), C_{0}$ is the initial concentration of fluoride $(\mathrm{mg} / \mathrm{L}), C_{t}$ is the concentration of fluoride in solution at given time $(\mathrm{mg} / \mathrm{L}), V$ is the solution volume (L), and $m$ is the adsorbent dosage $(\mathrm{g})$. The percentage removal is given by the following equation:

$$
A \%=\left(\frac{C_{0}-C_{t}}{C_{0}}\right) \times 100,
$$

where $A \%$ is the percentage of fluoride ions adsorbed and the remaining parameters are defined as in equation (1). 


\section{Results and Discussion}

3.1. Characterization of the Clay Composite Adsorbent Materials. The BET surface area of the different composite materials was determined using nitrogen physisorption as shown in Table 1 . The surface areas for the granules are $10 \mathrm{~m}^{2} / \mathrm{g}$ and $3 \mathrm{~m}^{2} / \mathrm{g}$ for $\mathrm{KBNPs}$ and $\mathrm{KB}$, respectively. The magnitude of the surface area gives an idea of possible available particles for adsorption. In general, the hysteresis is closely related to features of pore structure and underlying adsorption mechanism. There are two distinctive features of the type H3 loop: (i) the adsorption branch resembles a type II isotherm and (ii) the lower limit of the desorption branch is normally located at the cavitation-induced $p / p^{0}$. Loops of this type are given by nonrigid aggregates of plate-like particles. The type II isotherm results in the shape which is the result of unrestricted monolayer-multilayer adsorption up to high $p / p^{0}$. The scanning microscopic images for the adsorbents before and after adsorption are shown in Figures 2(a)-2(d). Both images confirm the plate-like behavior according to IUPAC description of the hysteresis of the BET. If the knee is sharp, Point B, the beginning of the middle almost linear section, usually corresponds to the completion of monolayer coverage. A more gradual curvature is an indication of a significant amount of overlap of monolayer coverage and the onset of multilayer adsorption. The thickness of the adsorbed multilayer generally appears to increase without limit when $\left(p / p^{0}\right)=1$.

The FTIR spectra of bentonite (B) and kaolinite clays (K) and the composites ( $\mathrm{KB}$ and KBNPs) are shown in Figures 3(a)-3(c). The bands between $3550 \mathrm{~cm}^{-1}$ and $4000 \mathrm{~cm}^{-1}$ corresponded to the structural hydroxyl groups and the water molecules in the interlayer space of the raw bentonite. FTIR spectrum of bentonite in the lower region shows bands at 1104, 1032, 976, 797, 695, 538, 470, and $433 \mathrm{~cm}^{-1}$. These bands are due to the vibrational modes of $\mathrm{SiO}_{4}$ tetrahedron.

The band at $3615 \mathrm{~cm}^{-1}$ was due to $\mathrm{O}-\mathrm{H}$ stretching, and a broad band centered on $3404 \mathrm{~cm}^{-1}$ was due to the interlayer and intralayer $\mathrm{H}$-bonded $\mathrm{O}-\mathrm{H}$ stretching. The band at $1637 \mathrm{~cm}^{-1}$ represented the $\mathrm{H}-\mathrm{O}-\mathrm{H}$ bending vibration of water, while the band at $1634 \mathrm{~cm}^{-1}$ might be attributed to the siloxane (-Si-O-Si-) group stretching. This indicates the possibility of the hydroxyl linkage between octahedral and tetrahedral layers. A very sharp and intense band is observed at $1634 \mathrm{~cm}^{-1}$ due to the asymmetric $\mathrm{OH}$ stretch (deformation mode) of water and is a structural part of the mineral. The band at $976 \mathrm{~cm}^{-1}$ is due to Al-OH and $662 \mathrm{~cm}^{-1}$.

The band observed at around $3620 \mathrm{~cm}^{-1}$ in the case of Figure 4 has been ascribed to the inner hydroxyls (crystalline hydroxyl), and the bands observed around the other three characteristic bands $\left(3684,3645\right.$, and $3620 \mathrm{~cm}^{-1}$ ) are generally ascribed to vibrations of the external hydroxyls. The bands in the $1000 \mathrm{~cm}^{-1}$ to $500 \mathrm{~cm}^{-1}$ region are dominated by functional groups $\mathrm{Si}-\mathrm{O}$ and $\mathrm{Al}-\mathrm{OH}$. The bands $788 \mathrm{~cm}^{-1}$ and $750 \mathrm{~cm}^{-1}$ are attributed to Si- quartz (as also in $1113 \mathrm{~cm}^{-1} \mathrm{Si}$ O quartz), whereas $996 \mathrm{~cm}^{-1}$ and $910 \mathrm{~cm}^{-1}$ are the vibrations due to $\mathrm{OH}$ deformation usually linked to $2 \mathrm{Al}^{3+}$.
After the adsorption experiments, the bands observed between 500 and $1030 \mathrm{~cm}^{-1}$ are characteristic vibrations of metal oxides $(\mathrm{Al} / \mathrm{Fe})$. The peaks observed at $3417-3660 \mathrm{~cm}^{-1}$ may be assigned to the $-\mathrm{OH}$ stretching frequencies of gibbsite or comparable metal oxide such as iron oxide [30]. After fluoride adsorption, intensity of the peaks was found to be decreased and shifted slightly to higher wavelength. Minor peaks observed from 1620 to $1652 \mathrm{~cm}^{-1}$, which could be assigned to the $\mathrm{H}-\mathrm{O}-\mathrm{H}$ bond stretching, disappeared or reduced drastically after the fluoride adsorption.

3.2. Effect of Contact Time. The effect of contact time is crucial in the understanding of the binding processes of fluoride ions and the time of equilibrium which strongly depends on factors such as pore structure of adsorbent, adsorbent particle size or surface area, and adsorbent concentration. The results obtained for percentage of fluoride removal as a function of contact time for the composite granules are presented in Figure 4. Kaolin-bentonite with nanoparticles (KBNPs) granules was found to have average percentage removal of $87 \%$ compared with the average value of $62 \%$ for kaolin-bentonite without nanoparticles (KB) representing $25 \%$ increase in fluoride removal when magnetic nanoparticles were combined with $\mathrm{KB}$. The BET hysteresis classification for both granules was described as type-II H3 which implies that the pores are slit-shaped pores, which appear to be more pronounced in the KBNPs. This could be responsible for the increase in adsorption observed in KBNPs. The maximum percentage removal for KBNPs and $\mathrm{KB}$ was $91 \%$ at 120 minutes and $68 \%$ at 140 minutes contact time, respectively. Both $\mathrm{KB}$ and KBNPs were found to have minimum percentage fluoride removal of $64 \%$ and $48 \%$, respectively, at 20 minutes' contact time. This preempts that adsorption of fluoride in the case of adsorbent under this study is therefore time-dependent. The sharp increase from 20 minutes' contact time to 120 minutes for both granules is due to the fact that initially all adsorbent sites were vacant and the solute concentration gradient was high $[31,32]$. Nevertheless, increase in contact time beyond $120 \mathrm{~min}$ did not increase the adsorption efficiency, which might be due to the presence of fewer adsorption sites and a lower fluoride ion concentration and/or as a result of competition for adsorption sites between fluoride and hydroxyl ions $[33,34]$. The asymptotic value obtained for both granules confirming equilibrium being established can be explained by minimal diminishing available sites for adsorption [35].

The phenomenon of adsorption is primarily dependent on particle size and/or active surface area. This implies that both powder and granules can be used for adsorption of fluoride ions. Although we adopted the use of granular ceramics, our studies compare well with reported studies where powders where employed. Kebede et al. [36] reported the use of iron ore (particle size less than $0.075 \mathrm{~mm}$ ) for fluoride adsorption with a percentage removal of $86 \%$ at $\mathrm{pH}$ 6 and after 120 minutes' contact time resulting in an adsorptive capacity of $\sim 1.72 \mathrm{mg} / \mathrm{g}$ [36]. Also, Puka found percentage removal of fluoride for kaolinite and bentonite 
TABLE 1: Adsorption isotherms' parameters and IUPAC classification for adsorbents granules.

\begin{tabular}{lccc}
\hline Clay composites & BET surface area $\left(\mathrm{m}^{2}\right)$ & Pore size, desorption $(\mathrm{nm})$ & Isotherm, hysteresis classification \\
\hline KB & 3 & 12 & Type II; H3 \\
KBNPs & 10 & 10 & Type II; H3 \\
\hline
\end{tabular}

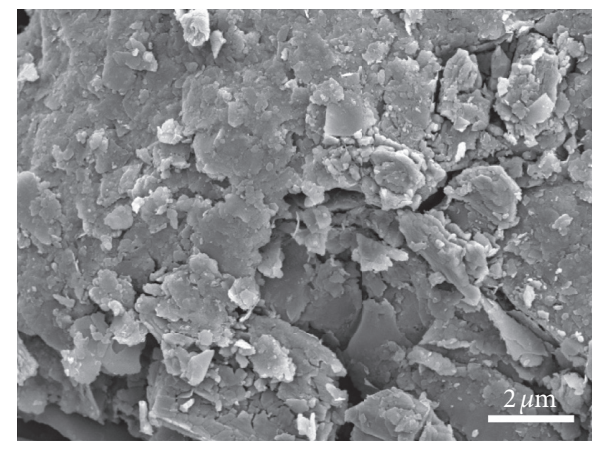

(a)

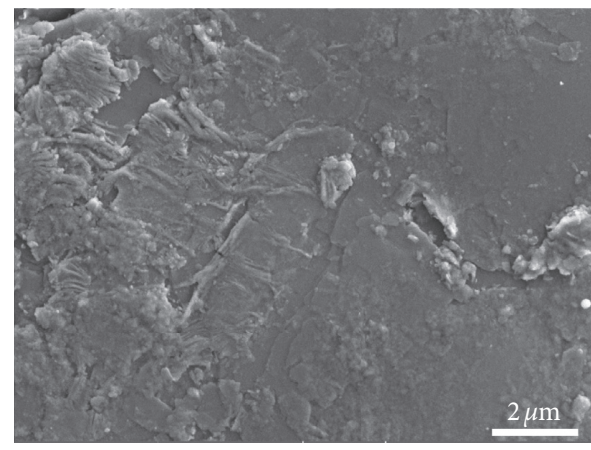

(c)

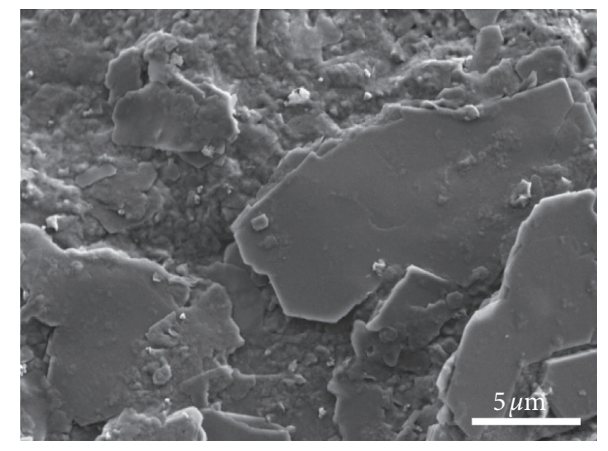

(b)

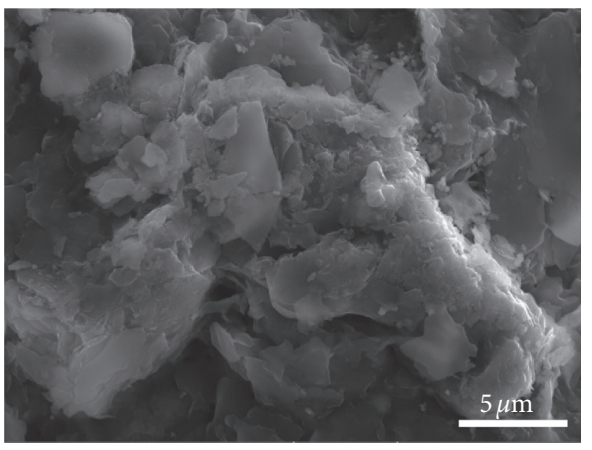

(d)

FIgURE 2: The SEM images of KB and KBNPs: before adsorption ((a) and (c)) and after adsorption ((b) and (d)).

coated with iron oxide to be $61 \%$ and $80 \%$, respectively. Furthermore, the maximum efficiency of fluoride removal has been documented as $92 \%$ at 120 minutes' contact time and equilibrium time for researchers which used powdered pyrolusite ore [37]. Longer contact time of 180 minutes has been reported by $[38,39]$, while contact time of 720 minutes has been reported by [40] to reach equilibrium adsorption. The effect of contact time on adsorption is not definitive and is dependent on factors such as competing ions in aqueous solution, particle size, pore structure, and nature of adsorbent surface.

3.3. Effect of Adsorbent Dosage. The effects of adsorbent dose on the removal efficiency of the fluoride ions by the granules were studied for the optimum conditions, and results are presented in Figure 5. The maximum percentage of fluoride removal for $\mathrm{KB}$ granule was found to be $86 \%$ at $25^{\circ} \mathrm{C}$ and for a contact time of 140 minutes, while that of KBNPs was $96 \%$ at the same temperature but at a contact time of 120 minutes. The dosage of $6 \mathrm{~g}$ of KBNPs and KB granules recorded the maximum removal efficiency. For example, from the $2 \mathrm{~g}$ to $6 \mathrm{~g}$ dosage recorded an increase from $68 \%$ to $86 \%$ for $\mathrm{KB}$ only. However, a reduction in the fluoride removal efficiency (reduced to $\sim 81 \%$ ) was observed when the adsorbent dosage was increased to $10 \mathrm{~g}$. Similar trend is observed for KBNPs, where it increases from $91 \%$ ( $2 \mathrm{~g}$ of adsorbent dose) to $96 \%$ (6 $\mathrm{g}$ of adsorbent dose) and then decreases to $91 \%$ (10 g of adsorbent dosage) from the maximum value.

Two main observed trends are documented: the increase in fluoride removal efficiency with increasing adsorbent dose has been observed in other literature such as Kim et al.'s work [41] and the decrease in removal efficiency from $6 \mathrm{~g}$ to $10 \mathrm{~g}$ adsorbent dose. The first trend is in agreement with Kim et al. who also reported an increase in fluoride removal efficiency from $25 \%$ to $98.5 \%$ at a fixed initial fluoride concentration when the adsorbent (pyrophyllite) dosage was increased [41]. Meenakshi et al. [42] and Thakre et al. [40] reported similar observations while experimenting on fluoride removal studies with kaolinite and bentonite and the increment is due to enhancement of the number of active sites available for adsorption of fluoride ions [40, 42].

The second observed trend which is the decrease in removal efficiency trend observed in the adsorbent dose $(6 \mathrm{~g}$ to $10 \mathrm{~g}$ ) in relation to fluoride removal efficiency can be described by two main reasons. These are (1) better utilization of the available active sites at low adsorbent dose in comparison to high adsorbent dose where too many sites are 


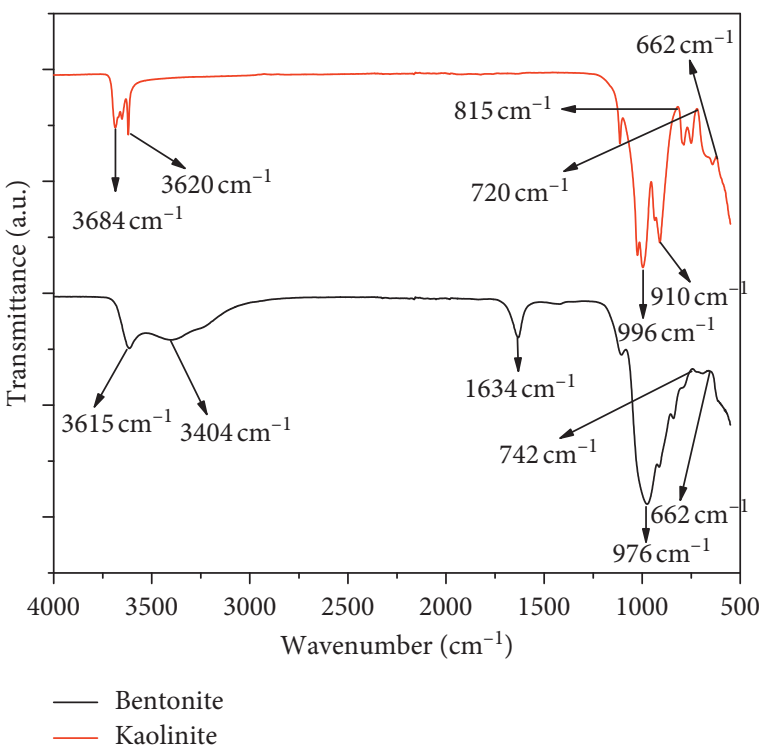

(a)

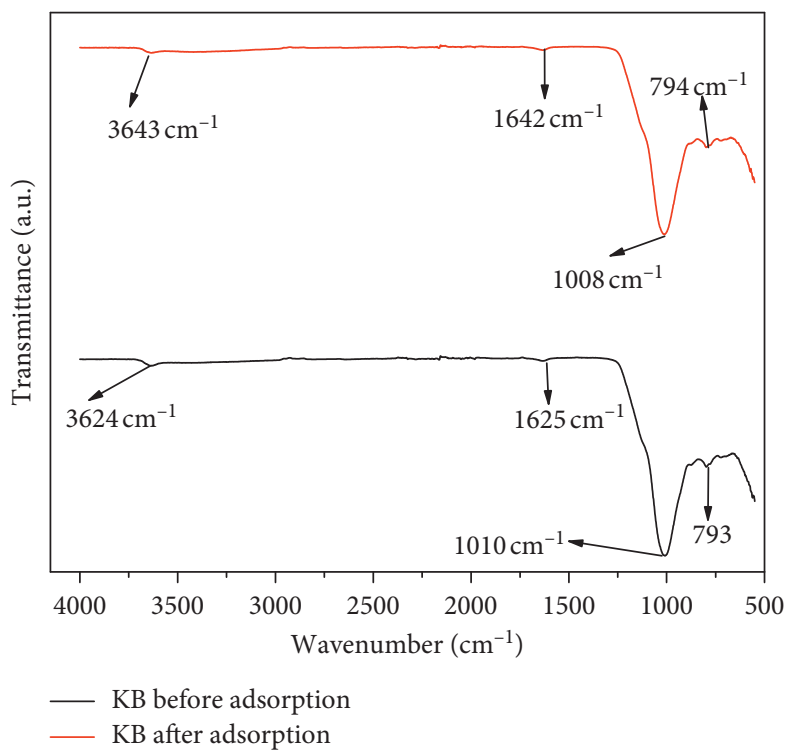

(b)

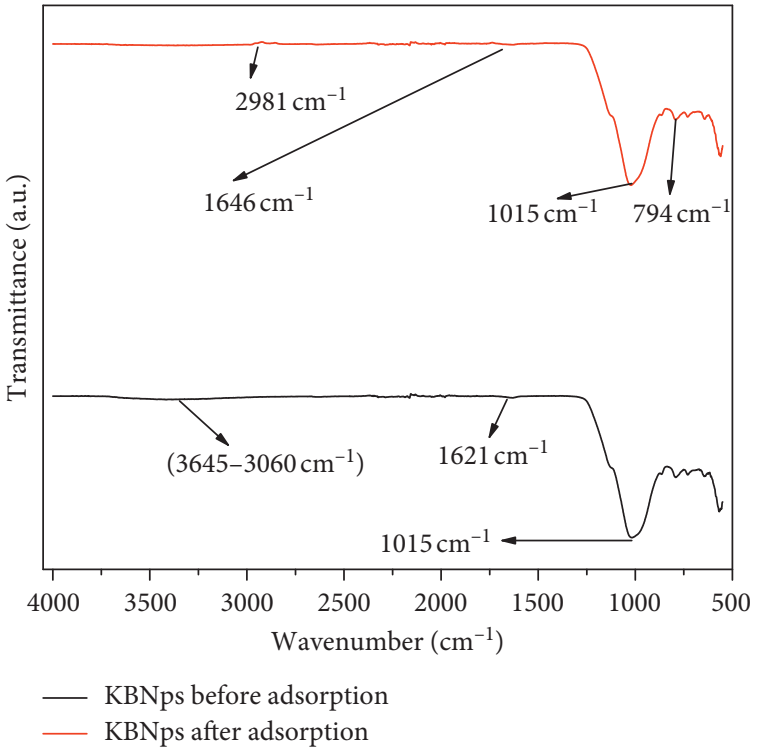

(c)

FIGURE 3: FTIR spectra for (a) bentonite and kaolinite clays, (b) KB composites, and (c) KBNPs composites before and after the adsorption experiments.

available for limited quantity of adsorbate and (2) reduced driving force for adsorption as high adsorbent dose causes low equilibrium fluoride concentration. Similar trends were reported by Maiti et al. [43] for laterite and by Goswami and Purkait [44] for pyrophyllite [43]. Goswami and Purkait [44] attributed the reduction to a decrease in adsorption capacity due to possible aggregation, overlapping, and overcrowding of adsorbent resulting in decreased available surface area [44].

3.4. Adsorption Kinetics and Isotherm Models. The experimental data for the fluoride adsorption was fitted to pseudofirst-order (equation (3)) and pseudo-second-order (equation (4)) kinetic models [45] and the plots are presented in Figure 6. The process kinetics described the solute uptake rate, thereby allowing the estimated residence time required to achieve a definite extent of fluoride removal $[46,47]$.

$$
\begin{aligned}
\log \left(q_{e}-q_{t}\right) & =\log q_{e}-\frac{k_{1}}{2.303} t, \\
\frac{t}{q_{t}} & =\frac{1}{\left(k_{2} q_{e}^{2}\right)}+\frac{t}{q_{e}},
\end{aligned}
$$

where $q_{e}$ and $q_{t}$ are the amount of fluoride adsorbed $(\mathrm{mg} / \mathrm{g})$ at equilibrium and any time $t$, respectively, and $k_{1}\left(\mathrm{~min}^{-1}\right)$ 


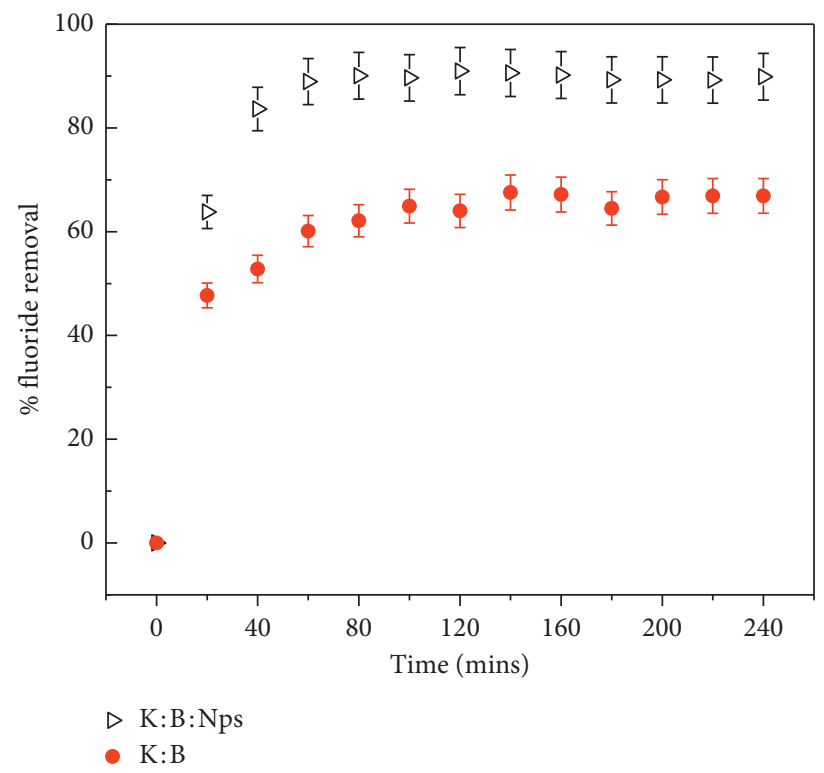

Figure 4: Effect of contact time on removal of fluoride.

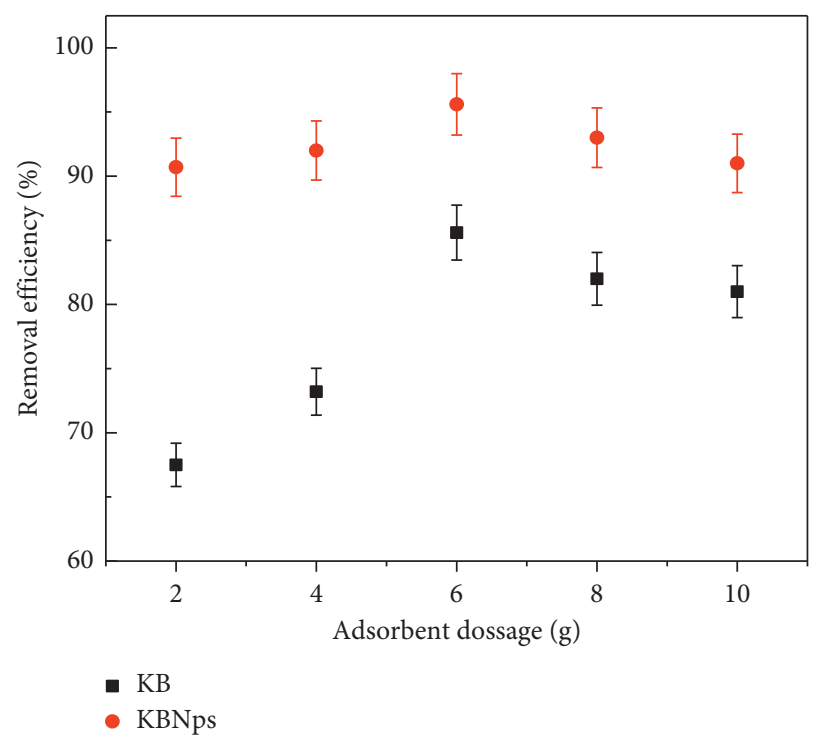

Figure 5: Effect of adsorbent dose on removal efficiency.

and $k_{2}\left(\mathrm{~min}^{-1}\right)$ are rate constants of adsorption for pseudofirst-order (PFO) and pseudo-second-order (PSO) models, respectively. From equation (3), a plot of $\log \left(q_{e}-q_{t}\right)$ versus time, $t$, results in a negative slope with gradient being $\left(k_{1}\right) /$ 2.303 and $\log \left(q_{e}\right)$ intercept on the vertical axis. Also, to deduce the parameters of adsorption in equation (4), $t / q_{t}$ is plotted against $t$ with slope $\left(1 / q_{e}\right)$ and intercept $\left(1 / k_{2} q_{e}^{2}\right)$ on the vertical $(t)$ axis.

The computed PFO and PSO parameters for these experiments are shown in Table 2 . The correlation coefficient $\left(R^{2}\right)$ value for the PSO model is higher than the PFO model in both samples. This indicates that the fluoride adsorption process on both granules can be described by chemisorption or valence forces process kinetic as expressed in other literature of modified clay minerals [40, 44, 48, 49]. The adsorptive capacity values computed for the PSO are also comparable to the measured experimental adsorptive capacity values. The calculated adsorption capacities at equilibrium for both samples for PSO are seen to be closer to the experimental adsorption capacity.

The Freundlich and Langmuir models are the two most widely used models to describe the mechanism for isotherm kinetics processes in adsorption processes. The Freundlich model is empirical, while the Langmuir equation assumes that the maximum adsorption occurs when the surface is covered by adsorbate in a monolayer [50]. Again, the Langmuir model assumes that the point of valence exists on the surface of the adsorbent and that each of these sites is 


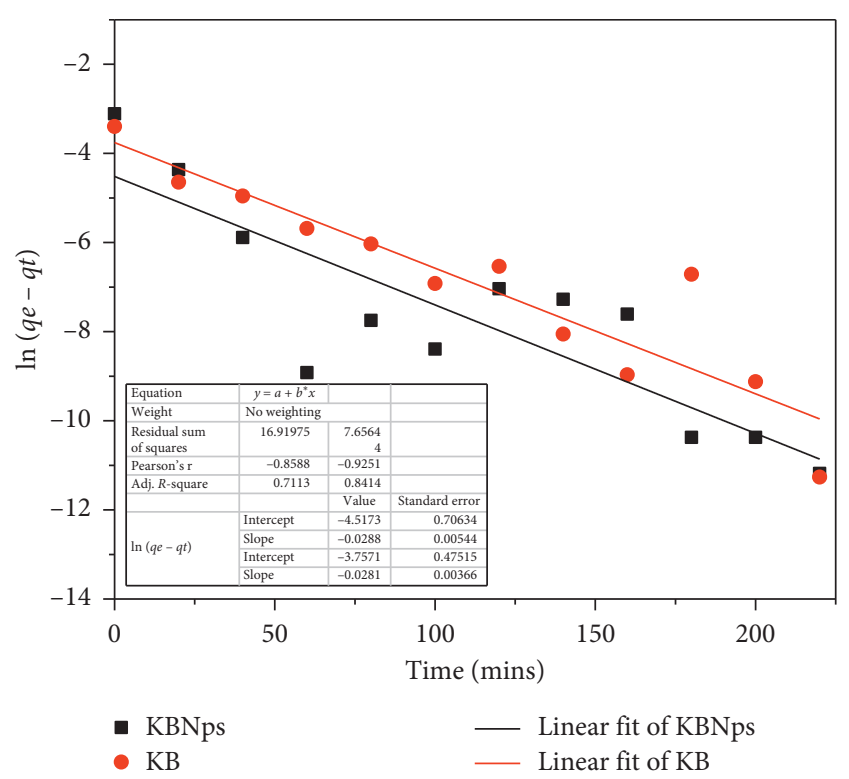

(a)

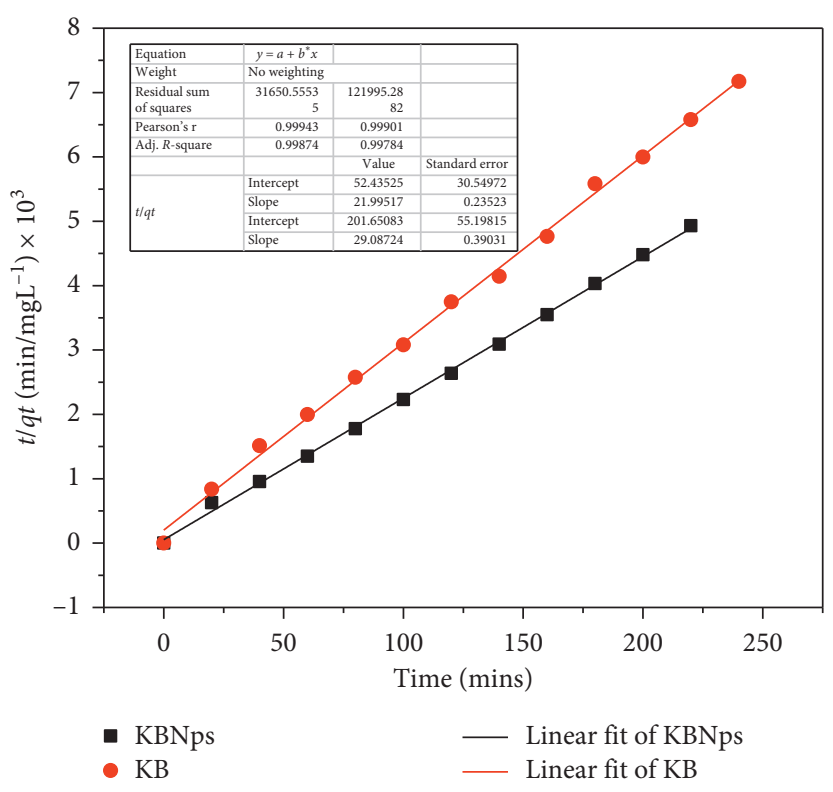

(b)

Figure 6: The kinetic models for KB and KBNPs adsorptions: first order (a) and second order (b).

TABLE 2: Kinetic models' parameters for adsorption of fluoride onto granules.

\begin{tabular}{lcccccr}
\hline \multirow{2}{*}{ Adsorbent } & \multirow{2}{*}{ Experiment $q_{e}(\mathrm{mg} / \mathrm{g})$} & \multicolumn{2}{c}{ Pseudo-first-order (PFO) } & \multicolumn{3}{c}{ Pseudo-second-order (PSO) } \\
& & $K_{1}\left(\mathrm{~min}^{-1}\right)$ & $q_{e}(\mathrm{mg} / \mathrm{g})$ & $R^{2}$ & $K_{2}(\mathrm{~g} / \mathrm{mg} / \mathrm{min})$ & $q_{e}(\mathrm{mg} / \mathrm{g})$ \\
\hline KBNPs & 0.045 & 0.066 & 0.011 & 0.77 & 9.22 & 0.046 \\
KB & 0.033 & 0.109 & 0.098 & 0.60 & 4.19 & 0.99 \\
\hline
\end{tabular}

capable of adsorbing one molecule. Furthermore, it is assumed that the adsorption sites have equal affinities for molecules of adsorbate and that the presence of adsorbed molecules at one site will not affect the adsorption of molecules at an adjacent site [2]. Both models are applied to understand the mechanism and quantify the adsorption capacity of the adsorbent for the removal of fluoride ions from aqueous solutions.

The Langmuir and Freundlich equations are given in equations (5) and (6), respectively. The computed parameters for both models are given in Table 3.

$$
\begin{aligned}
& \text { Original form: } q_{e}=\frac{q_{m} K_{L} C_{e}}{1+K_{L} C_{e}}, \\
& \text { linearized form: } \frac{C_{e}}{q_{e}}=\frac{1}{K_{L} q_{m}}+\frac{1}{q_{m}} * C_{e}, \\
& \text { Original form: } q_{e}=K_{F} * C_{e}^{(1 / n)}, \\
& \text { linearized form: } \log q_{e}=\log K_{F}+\frac{1}{n} \log C_{e},
\end{aligned}
$$

where $K_{L}$ and $q_{m}$ are Langmuir constants related to adsorption intensity $(\mathrm{L} / \mathrm{mg})$ and maximum adsorption capacity $(\mathrm{mg} / \mathrm{g})$, respectively; $q_{e}$ is the equilibrium adsorption capacity $(\mathrm{mg} / \mathrm{g}), K_{F}$ and $(1 / n)$ are the Freundlich constants, related to the minimum adsorption capacity and adsorption intensity, respectively, and $C_{e}$ is the equilibrium concentration $(\mathrm{mg} / \mathrm{L})$. In these isotherms, when the Langmuir favorability factor ( $K_{L}$ factor), $0<K_{L}<1$, the adsorption is influenced by the Langmuir isotherm. However, when the heterogeneity factor $(n)$ is greater than $1(n>1)$, the adsorption is usually influenced by the Freundlich model.

The obtained experimental results in this study were fitted with the Langmuir and Freundlich isotherm models and are presented in Figures 7(a) and 7(b). From Figure 7(a), it can be seen from the experimental results that the equilibrium adsorption capacity increased with increasing equilibrium concentration of the fluoride ions when $\mathrm{KB}$ granules were used as the adsorbent. $R^{2}$ values of 0.87 and 0.86 were obtained when the experimental results were fitted with Freundlich and Langmuir adsorption isotherm models, respectively. From the $R^{2}$ values, the adsorption of fluoride ions on $\mathrm{KB}$ granules can be explained by a combined mechanism of Langmuir and Freundlich adsorption models [51-54]. However, considering heterogeneity factor $(n)$ value of 0.518 which is less than 1 , the adsorption of fluoride ions on KB by the Freundlich isotherm model may not be favorable. The Langmuir favorability factor $\left(R_{L}\right.$ factor $)$ was estimated to be 0.444 . Since this value is less than 1 , adsorption of fluoride ions by KB is favorable [55]. Therefore, the adsorption of fluoride ions by KB most likely followed 
TABLE 3: Adsorption isotherm models' parameters for adsorption of fluoride onto granules.

\begin{tabular}{lccccr}
\hline \multirow{2}{*}{ Adsorbent } & \multicolumn{3}{c}{ Langmuir isotherm model } & \multicolumn{3}{c}{ Freundlich isotherm model } \\
& $K_{L}(\mathrm{~L} / \mathrm{mg})$ & $q_{\max }(\mathrm{mg} / \mathrm{g})$ & $R^{2}$ & $K_{F}(\mathrm{mg} / \mathrm{g})(\mathrm{min})$ & $n(\mathrm{mg} / \mathrm{g})(\mathrm{L} / \mathrm{mg})^{1 / n}$ \\
\hline KBNPs & 90.5 & 0.047 & 0.85 & 0.048 & 20.0 \\
KB & 0.625 & 0.035 & 0.86 & 0.056 & 0.918 \\
\hline
\end{tabular}

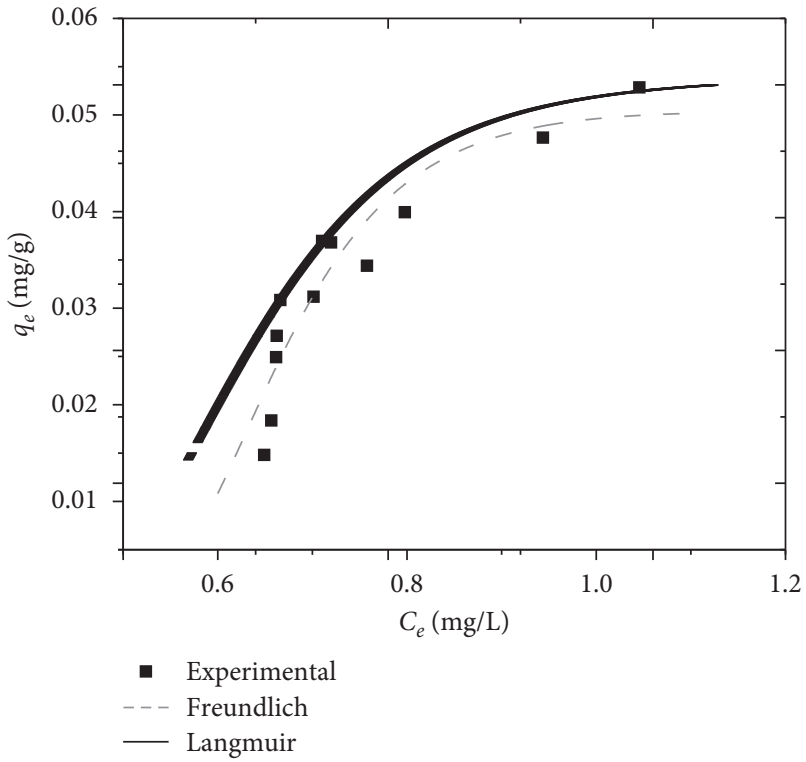

(a)

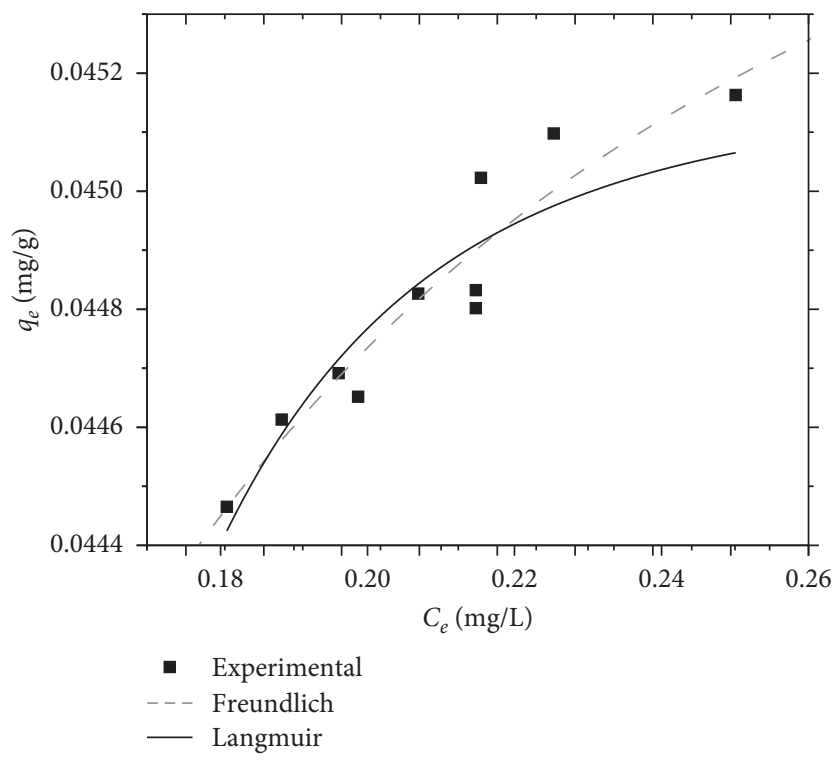

(b)

FIGURE 7: Isotherm model description for adsorbents: (a) KB adsorption and (b) KBNPs adsorption.

the Langmuir model. The Langmuir and Freundlich constants obtained from the linearized Langmuir and Freundlich equations (in equations (5) and (6)) are presented in Table 3. The experimental results of the KBNps adsorption of fluoride ions were also fitted with the Langmuir and Freundlich isotherms and the results presented in Figure 7(b). It can be inferred from Figure 7(b) that the equilibrium adsorption capacity increased with increasing equilibrium concentration of the fluoride ions. However, the equilibrium adsorption capacity almost plateaued between fluoride equilibrium concentrations of 0.22 and $0.26 \mathrm{mg} / \mathrm{L}$. By fitting the experimental data with the Langmuir and Freundlich models, $R^{2}$ values of 0.86 and 0.90 were, respectively, obtained. Therefore, by incorporating iron oxide nanoparticles into the $\mathrm{KB}$ granules, the adsorption mechanism slightly shifted towards the Freundlich adsorption isotherm model. With a recorded heterogeneity factor value greater than 1, it implies that the adsorption of fluoride ions on KBNPs is favorable. The adsorption of fluoride ions by KBNPs therefore followed the Freundlich isotherm model. This agrees with several scholarly papers that show that fluoride adsorption unto clay minerals can best be described with Freundlich isotherm model $[33,55,56]$. The Langmuir and Freundlich constants obtained from the linearized Langmuir and Freundlich equations (in equations (5) and (6)) are presented in Table 3.
3.5. Proposed Mechanism for Fluoride Adsorption. Loganathan et al. [57] proposed five mechanisms for fluoride adsorption. They are (1) van der Waals forces (outer-sphere surface complexation), (2) ion exchange (outer-sphere surface complexation), (3) hydrogen bonding ( $\mathrm{H}$-bonding) (inner-sphere surface complexation), (4) ligand exchange (inner-sphere surface complexation), and (5) chemical modification of the adsorbent surface [57]. The schematics of the mechanisms are shown in Figure 8 . The first two mechanisms are governed by weak physical adsorption and are nonspecific to fluoride, where in the presence of other competing anions they cannot be used to remove fluoride. The third and fourth mechanisms are governed by strong chemical adsorption specific to fluoride and capable of removing fluoride selectively in the presence of other anions such as phosphates. The fifth mechanism is governed by both specific and nonspecific adsorption.

In this study, we propose the mechanism in Figure 8 to explain the fluoride adsorption in the use of the granules. Clays are known to have mainly silica and alumina, with proportional quantities of various metal oxides. The clay minerals were doped with magnetite nanoparticles, which will modify both internal and exterior surface properties. The adsorption capacity of fluoride on adsorbents can be increased by chemical modification of adsorbent surfaces [58-60]. This is particularly of advantage in the case of 


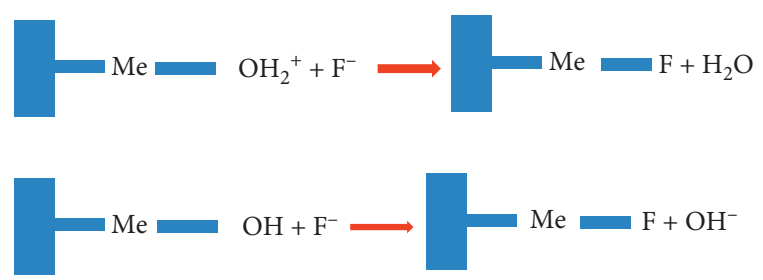

Figure 8: Adopted mechanism for fluoride adsorption ( $\square$-adsorbent; $\mathrm{Me}$, multivalent metallic cation) [57].

adsorbents possessing negative surface and when they are impregnated onto the adsorbent to create positive charges on the adsorbent surface, they attract fluoride by Coulombic forces and produce adsorption sites capable of chemical interaction with fluoride. These metallic cations act as a bridge in adsorbing fluoride onto the adsorbent. Based on general mechanism proposed in Section 3.5, the possible specific reaction mechanism for adsorption of fluoride onto granular ceramic can be hypothesized as follows:

$$
2 \mathrm{Fe}_{3} \mathrm{O}_{4}+\mathrm{H}_{2} \mathrm{O} \rightleftarrows 3 \mathrm{Fe}_{2} \mathrm{O}_{3}+2 \mathrm{H}^{+}(\mathrm{R} 1)
$$
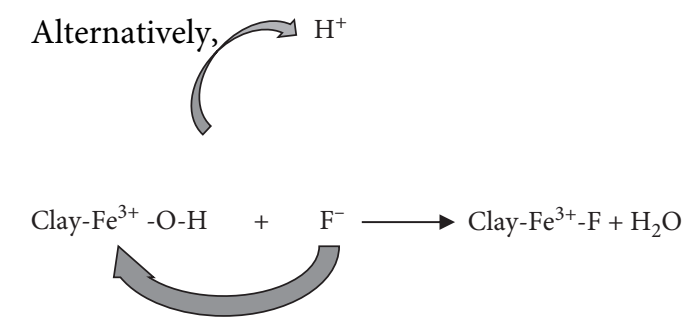

$$
\begin{gathered}
\mathrm{Fe}_{2} \mathrm{O}_{3}+\mathrm{H}_{2} \mathrm{O} \longrightarrow \mathrm{Fe}(\mathrm{OH})_{3}(\mathrm{R} 3) \\
\text { Clay }-\mathrm{Fe}(\mathrm{OH})_{3-x}+\mathrm{F}^{-} \longrightarrow \text { Clay }-\mathrm{Fe}_{2}-\mathrm{F}+\mathrm{XOH}(\mathrm{R} 4)
\end{gathered}
$$

The parent material in the production of the granules is mainly aluminosilicate materials, which is clay. Metal oxides, especially multivalent ions such as $\mathrm{Al}^{3+}$ and $\mathrm{Fe}^{3+}$, are crucial in the adsorption of fluoride. In reaction (R1), possible breakdown is envisaged for the magnetite, which modifies the surface of the granule. Reaction (R2) explains iron (III) oxide in presence of water, protonation, and fluoride attachment with multivalent ion. Alternatively, the formation of iron hydroxide (in reaction R3) is also paramount to fluoride adsorption. During the formation of iron hydroxide, the fluoride ions present in the aqueous solution would replace the hydroxyl ions in the iron crystal lattice without disturbing the crystal structure of the compound as in reaction (R4). A similar process would occur in the presence of aluminum oxide. This isoelectronic property is possible because $\mathrm{F}^{-}$and $\mathrm{OH}^{-}$ions are of similar size, with comparable ionic radii [61].

\section{Conclusion and Recommendations}

This work demonstrates the feasibility of removing fluoride from drinking water using modified clay composites with magnetite nanoparticles (KB and KBNPs). The maximum percentage removal for KBNPs and KB adsorbents was 91\% after 120 minutes' contact time and 68\% after 140 minutes' contact time, respectively. Both sets of granules were found to have minimum percentage removal after 20 minutes' contact time with the recorded fluoride removal efficiencies of $\sim 64 \%$ and $\sim 48 \%$ for KBNPs and KB, respectively. The increase in removal efficiency is demonstrated via the addition of magnetite nanoparticles. For optimum conditions, the maximum percentage of fluoride removal for $\mathrm{KB}$ granule was found to be $86 \%$ at $25^{\circ} \mathrm{C}$ (for adsorbent dosage of $6 \mathrm{~g}$ ) and for a contact time of 140 minutes, while that of KBNPs was $96 \%$ at $25^{\circ} \mathrm{C}$ but at a contact time of 120 minutes. The adsorption of fluoride by both adsorbents can be best described with Freundlich isotherm model. The pseudo-second-order kinetic model had higher $R$-squared value and best describes the mechanism for both $\mathrm{KB}$ and KBNPs adsorbents. This work clearly shows a feasible sustainable approach for the design of filtration systems for the removal of fluoride from groundwater using mainly locally sourced, accessible, and cheap components.

\section{Data Availability}

This article is part of an ongoing project and the data cannot be shared at the moment. The entire data will be available when the project is completed.

\section{Conflicts of Interest}

The authors declare that there are no conflicts of interest.

\section{Acknowledgments}

This project was funded by Cambridge-Africa Partnership for Research Excellence (CAPREx) Project and ALBORADA research fund at the University of Ghana, Legon, Ghana. Benjamin Agyei-Tuffour acknowledges the support of the University of Ghana BANGA-Africa Programme.

\section{References}

[1] World Health Organization, Guidelines for Drinking-Water Quality, World Health Organization, Geneva, Switzerland, 2004.

[2] M. Mahramanlioglu, I. Kizilcikli, and I. O. Bicer, "Adsorption of fluoride from aqueous solution by acid treated spent bleaching earth," Journal of Fluorine Chemistry, vol. 115, no. 1, pp. 41-47, 2002.

[3] N. Chinoy, "Effects of fluoride on physiology of animals and human beings," Indian Journal of Environmental Toxicology, vol. 1, no. 1, pp. 17-32, 1991.

[4] P. T. Harrison, "Fluoride in water: a UK perspective," Journal of Fluorine Chemistry, vol. 126, no. 11-12, pp. 1448-1456, 2005.

[5] X. Fan, D. J. Parker, and M. D. Smith, "Adsorption kinetics of fluoride on low cost materials," Water Research, vol. 37, no. 20, pp. 4929-4937, 2003.

[6] D. Banks, C. Reimann, O. Røyset, H. Skarphagen, and O. M. Sæther, "Natural concentrations of major and trace 
elements in some Norwegian bedrock groundwaters," Applied Geochemistry, vol. 10, no. 1, pp. 1-16, 1995.

[7] W. B. Apambire, D. R. Boyle, and F. A. Michel, "Geochemistry, genesis, and health implications of fluoriferous groundwaters in the upper regions of Ghana," Environmental Geology, vol. 33, no. 1, pp. 13-24, 1997.

[8] N. Reddy and K. Prasad, "Pyroclastic fluoride in ground waters in some parts of Tadpatri Taluk, Anantapur district, Andhra Pradesh," Indian Journal of Environmental Health, vol. 45, no. 4, pp. 285-288, 2003.

[9] E. J. Reardon and Y. Wang, "A limestone reactor for fluoride removal from wastewaters," Environmental Science \& Technology, vol. 34, no. 15, pp. 3247-3253, 2000.

[10] K. M. K. Kut, A. Sarswat, A. Srivastava, C. U. Pittman Jr., and D. Mohan, "A review of fluoride in African groundwater and local remediation methods," Groundwater for Sustainable Development, vol. 2-3, pp. 190-212, 2016.

[11] B. G. Survey, "Fluoride in groundwater," March 2019.

[12] M. Sutton, R. Kiersey, L. Farragher, and J. Long, "Health effects of water fluoridation," Technical Report, Health Research Board, Dublin, Ireland, 2015.

[13] L. R. Puka, Fluoride Adsorption Modelling and the Characterization of Clays for Defluoridation of Natural Waters, University of Johannesburg, Johannesburg, South Africa, 2008.

[14] N. Das, P. Pattanaik, and R. Das, "Defluoridation of drinking water using activated titanium rich bauxite," Journal of Colloid and Interface Science, vol. 292, no. 1, pp. 1-10, 2005.

[15] H. Lounici, L. Addour, D. Belhocine et al., "Study of a new technique for fluoride removal from water," Desalination, vol. 114, no. 3, pp. 241-251, 1997.

[16] D. Mohapatra, D. Mishra, S. P. Mishra, G. R. Chaudhury, and R. P. Das, "Use of oxide minerals to abate fluoride from water," Journal of Colloid and Interface Science, vol. 275, no. 2, pp. 355-359, 2004.

[17] A. Raichur and M. J. Basu, "Adsorption of fluoride onto mixed rare earth oxides," Separation and Purification Technology, vol. 24, no. 1-2, pp. 121-127, 2001.

[18] M. Agarwal, K. Rai, R. Shrivastav, and S. Dass, "Deflouridation of water using amended clay," Journal of Cleaner Production, vol. 11, no. 4, pp. 439-444, 2003.

[19] S. A. Wasay, M. J. Haran, and S. Tokunaga, "Adsorption of fluoride, phosphate, and arsenate ions on lanthanum-impregnated silica gel," Water Environment Research, vol. 68, no. 3, pp. 295-300, 1996.

[20] I. Abe, S. Iwasaki, T. Tokimoto, N. Kawasaki, T. Nakamura, and S. Tanada, "Adsorption of fluoride ions onto carbonaceous materials," Journal of Colloid and Interface Science, vol. 275, no. 1, pp. 35-39, 2004.

[21] Y. Çengeloglu, E. Kır, and M. Ersöz, "Removal of fluoride from aqueous solution by using red mud," Separation and Purification Technology, vol. 28, no. 1, pp. 81-86, 2002.

[22] R. Piekos and S. Paslawska, "Fluoride uptake characteristics of fly ash," Fluoride, vol. 32, pp. 14-19, 1999.

[23] N. V. R. M. Rao and C. S. Bhaskaran, "Studies on defluoridation of water," Journal of Fluorine Chemistry, vol. 41, no. 1, pp. 17-24, 1988.

[24] S. V. Mohan, S. Ramanaiah, B. Rajkumar, and P. Sarma, "Removal of fluoride from aqueous phase by biosorption onto algal biosorbent Spirogyra sp.-IO2: sorption mechanism elucidation," Journal of Hazardous Materials, vol. 141, no. 3, pp. 465-474, 2007.

[25] J. Qiao, Z. Cui, Y. Sun, Q. Hu, and X. Guan, "Simultaneous removal of arsenate and fluoride from water by Al-Fe (hydr) oxides," Frontiers of Environmental Science \& Engineering, vol. 8, no. 2, pp. 169-179, 2014.
[26] V. Tomar and D. Kumar, "A critical study on efficiency of different materials for fluoride removal from aqueous media," Chemistry Central Journal, vol. 7, no. 1, p. 51, 2013.

[27] X. Dou, Y. Zhang, H. Wang, T. Wang, and Y. Wang, "Performance of granular zirconium-iron oxide in the removal of fluoride from drinking water," Water Research, vol. 45, no. 12, pp. 3571-3578, 2011.

[28] M. Mohapatra, S. Anand, B. K. Mishra, D. E. Giles, and P. Singh, "Review of fluoride removal from drinking water," Journal of Environmental Management, vol. 91, no. 1, pp. 67-77, 2009.

[29] P. Kau, D. Smith, and P. Binning, "Experimental sorption of fluoride by kaolinite and bentonite," Geoderma, vol. 84, no. 1-3, pp. 89-108, 1998.

[30] S. G. Wang, Y. Ma, Y. J. Shi, and W. X. Gong, "Defluoridation performance and mechanism of nano-scale aluminum oxide hydroxide in aqueous solution," Journal of Chemical Technology and Biotechnology: International Research in Process, Environmental Clean Technology, vol. 84, no. 7, pp. 10431050, 2009.

[31] E. Tchomgui-Kamga, V. Alonzo, C. P. Nanseu-Njiki, N. Audebrand, E. Ngameni, and A. Darchen, "Preparation and characterization of charcoals that contain dispersed aluminum oxide as adsorbents for removal of fluoride from drinking water," Carbon, vol. 48, no. 2, pp. 333-343, 2010.

[32] E. Tchomgui-Kamga, E. Ngameni, and A. Darchen, "Evaluation of removal efficiency of fluoride from aqueous solution using new charcoals that contain calcium compounds," Journal of Colloid and Interface Science, vol. 346, no. 2, pp. 494-499, 2010.

[33] N. Chen, Z. Zhang, C. Feng, N. Sugiura, M. Li, and R. Chen, "Fluoride removal from water by granular ceramic adsorption," Journal of Colloid and Interface Science, vol. 348, no. 2, pp. 579-584, 2010.

[34] A. Tembhurkar and S. Dongre, "Studies on fluoride removal using adsorption process," Journal of Environmental Science \& Engineering, vol. 48, no. 3, pp. 151-156, 2006.

[35] A. Vinati, B. Mahanty, and S. K. Behera, "Clay and clay minerals for fluoride removal from water: a state-of-the-art review," Applied Clay Science, vol. 114, pp. 340-348, 2015.

[36] B. Kebede, A. Beyene, F. Fufa, M. Megersa, and M. Behm, "Experimental evaluation of sorptive removal of fluoride from drinking water using iron ore," Applied Water Science, vol. 6, no. 1, pp. 57-65, 2016.

[37] N. Thi Hue and N. Hoang Tung, "Study about doping ion $\mathrm{La}^{3+}$ onto surface of pyrolusite ore for removing simultaneously both fluoride and phosphate from wastewater," Journal of Chemistry, vol. 2017, Article ID 4893835, 11 pages, 2017.

[38] D. Mehta, P. Mondal, and S. George, "Utilization of marble waste powder as a novel adsorbent for removal of fluoride ions from aqueous solution," Journal of Environmental Chemical Engineering, vol. 4, no. 1, pp. 932-942, 2016.

[39] W. Xiang, G. Zhang, Y. Zhang, D. Tang, and J. Wang, "Synthesis and characterization of cotton-like Ca-Al-La composite as an adsorbent for fluoride removal," Chemical Engineering Journal, vol. 250, pp. 423-430, 2014.

[40] D. Thakre, S. Rayalu, R. Kawade, S. Meshram, J. Subrt, and N. Labhsetwar, "Magnesium incorporated bentonite clay for defluoridation of drinking water," Journal of Hazardous Materials, vol. 180, no. 1-3, pp. 122-130, 2010.

[41] J.-H. Kim, C.-G. Lee, J.-A. Park, J.-K. Kang, N.-C. Choi, and S.-B. Kim, "Use of pyrophyllite clay for fluoride removal from aqueous solution," Desalination and Water Treatment, vol. 51, no. 16-18, pp. 3408-3416, 2013. 
[42] S. Meenakshi, C. S. Sundaram, and R. Sukumar, "Enhanced fluoride sorption by mechanochemically activated kaolinites," Journal of Hazardous Materials, vol. 153, no. 1-2, pp. 164-172, 2008.

[43] A. Maiti, J. K. Basu, and S. De, "Chemical treated laterite as promising fluoride adsorbent for aqueous system and kinetic modeling," Desalination, vol. 265, no. 1-3, pp. 28-36, 2011.

[44] A. Goswami and M. K. Purkait, "Kinetic and equilibrium study for the fluoride adsorption using pyrophyllite," Separation Science and Technology, vol. 46, no. 11, pp. 1797-1807, 2011.

[45] Y. S. Ho and G. McKay, "Pseudo-second order model for sorption processes," Process Biochemistry, vol. 34, no. 5, pp. 451-465, 1999.

[46] J. Lin and L. Wang, "Comparison between linear and nonlinear forms of pseudo-first-order and pseudo-second-order adsorption kinetic models for the removal of methylene blue by activated carbon," Frontiers of Environmental Science \& Engineering in China, vol. 3, no. 3, pp. 320-324, 2009.

[47] L. Pontoni and M. Fabbricino, "Use of chitosan and chitosanderivatives to remove arsenic from aqueous solutions-a mini review," Carbohydrate Research, vol. 356, pp. 86-92, 2012.

[48] N. Chen, Z. Zhang, C. Feng, M. Li, D. Zhu, and N. Sugiura, "Studies on fluoride adsorption of iron-impregnated granular ceramics from aqueous solution," Materials Chemistry Physics, vol. 125, no. 1-2, pp. 293-298, 2011.

[49] V. Masindi, "Application of cryptocrystalline magnesitebentonite clay hybrid for defluoridation of underground water resources: implication for point of use treatment," Journal of Water Reuse and Desalination, vol. 7, no. 3, pp. 338-352, 2017.

[50] H. Freundlich, "Over the adsorption in solution," The Journal of Physical Chemistry, vol. 57, no. 1906, pp. 385-471, 1906.

[51] M. Dessalegne, F. Zewge, and I. Diaz, "Aluminum hydroxide supported on zeolites for fluoride removal from drinking water," Journal of Chemical Technology \& Biotechnology, vol. 92, no. 3, pp. 605-613, 2017.

[52] W. M. Gitari, T. Ngulube, V. Masindi, and J. R. Gumbo, "Defluoridation of groundwater using $\mathrm{Fe}^{3+}$-modified bentonite clay: optimization of adsorption conditions," Desalination and Water Treatment, vol. 53, no. 6, pp. 1578-1590, 2015

[53] R. Mudzielwana, M. W. Gitari, and T. A. Msagati, "Characterisation of smectite-rich clay soil: implication for groundwater defluoridation," South African Journal of Science, vol. 112, no. 11-12, pp. 1-8, 2016.

[54] S. Zhang, Y. Lyu, X. Su, Y. Bian, B. Yu, and Y. Zhang, "Removal of fluoride ion from groundwater by adsorption on lanthanum and aluminum loaded clay adsorbent," Environmental Earth Sciences, vol. 75, no. 5, p. 401, 2016.

[55] M. K. Uddin, S. S. Ahmed, and M. Naushad, "A mini update on fluoride adsorption from aqueous medium using clay materials," Desalination and Water Treatment, vol. 145, pp. 232-248, 2019.

[56] A. Tor, N. Danaoglu, G. Arslan, and Y. Cengeloglu, "Removal of fluoride from water by using granular red mud: batch and column studies," Journal of Hazardous Materials, vol. 164, no. 1, pp. 271-278, 2009.

[57] P. Loganathan, S. Vigneswaran, J. Kandasamy, and R. Naidu, "Defluoridation of drinking water using adsorption processes," Journal of Hazardous Materials, vol. 248-249, pp. 119,2013

[58] S. Samatya, Ü. Yüksel, M. Yüksel, and N. Kabay, "Removal of fluoride from water by metal ions $\left(\mathrm{Al}^{3+}, \mathrm{La}^{3+}\right.$ and $\left.\mathrm{ZrO}^{2+}\right)$
Loaded Natural Zeolite," Separation Science and Technology, vol. 42, no. 9, pp. 2033-2047, 2007.

[59] S.-X. Teng, S.-G. Wang, W.-X. Gong, X.-W. Liu, and B.-Y. Gao, "Removal of fluoride by hydrous manganese oxidecoated alumina: performance and mechanism," Journal of Hazardous Materials, vol. 168, no. 2-3, pp. 1004-1011, 2009.

[60] Y. Zhou, C. Yu, and Y. Shan, "Adsorption of fluoride from aqueous solution on $\mathrm{La}^{3+}$-impregnated cross-linked gelatin," Separation and Purification Technology, vol. 36, no. 2, pp. 89-94, 2004

[61] S. M. Maliyekkal, S. Shukla, L. Philip, and I. M. Nambi, "Enhanced fluoride removal from drinking water by magnesia-amended activated alumina granules," Chemical Engineering Journal, vol. 140, no. 1-3, pp. 183-192, 2008. 